\title{
Relationship between glycemic control and $O P G$ gene polymorphisms with lower bone mineral density in patients with type 1 Diabetes mellitus
}

\author{
Melina Bezerra Loureiro ${ }^{1}$, Marcela Abbott Galvão Ururahy ${ }^{1}$, Karla Simone Costa de Souza ${ }^{1}$, \\ Yonara Monique da Costa Oliveira ${ }^{1}$, Heglayne Pereira Vital da Silva ${ }^{1}$, Raul Hernandes Bortolin ${ }^{1}$, \\ João Felipe Bezerra', Rosario Dominguez Crespo Hirata ${ }^{2}$, José Jorge Maciel-Neto ${ }^{3}$, \\ Ricardo Fernando Arrais ${ }^{4}$, Maria das Graças Almeida ${ }^{1}$, Mario Hiroyuki Hirata ${ }^{2}$, \\ Adriana Augusto de Rezende ${ }^{1 *}$
}

\begin{abstract}
'Department of Clinical and Toxicological Analyses, Federal University of Rio Grande do Norte, Natal, RN, Brazil, ${ }^{2}$ Department of Clinical and Toxicological Analyses, University of São Paulo, São Paulo, SP, Brazil, ${ }^{3}$ Department of Radiology, Federal University of Rio Grande do Norte, Natal, RN, Brazil, ${ }^{4}$ Department of Pediatrics, Federal University of Rio Grande do Norte, Natal, RN, Brazil
\end{abstract}

\begin{abstract}
The aim of the present study was to investigate the bone mineral density (BMD) of patients with type 1 Diabetes mellitus (T1DM). We also assessed the association between osteoprotegerin (OPG) genetic polymorphisms and BMD. Genotyping was performed for $1181 \mathrm{G}>\mathrm{C}$ and $163 \mathrm{~A}>\mathrm{G} O P G$ polymorphisms by allelic discrimination in 119 patients with T1DM and 161 normoglycemic (NG) individuals, aged 6 to 20 years old. Glycemic control, serum parameters of bone metabolism and BMD were evaluated. T1DM patients showed low BMD, poor glycemic control and decreased total calcium values when compared to controls $(p<0.05)$. For all the polymorphisms studied, the genotype and allele frequencies in patients with T1DM were not significantly different from the controls. In patients with T1DM, carriers of $O P G 1181 \mathrm{CC}$ showed higher concentrations of ionized calcium compared to patients with $\mathrm{GG}+\mathrm{GC}$ genotypes. These results suggest that low BMD is associated with poor glycemic control in T1DM. Despite the lack of a detected association between $O P G$ polymorphisms and BMD in these patients, the increased ionized calcium in those carrying $O P G 1181 \mathrm{CC}$ suggests a possible increase in osteoclastogenesis, a conclusion that may be supported by the lower BMD observed in these subjects.
\end{abstract}

Keywords: Type 1 Diabetes mellitus/bone biomarkers. Bone mineral density. OPG polymorphism/ children and adolescents.

\section{INTRODUCTION}

Type 1 Diabetes mellitus (T1DM) is an autoimmune disease in which pancreatic beta cells are selectively destroyed, leading to chronic hyperglycemia and consequentially long-term vascular complications such as retinopathy, neuropathy, nephropathy and osteopathy (American Diabetes Association, 2016). More than $50 \%$ of patients with T1DM have bone loss compared

\footnotetext{
*Corresponding author: A. A. Rezende. Faculdade de Farmácia, Universidade Federal do Rio Grande do Norte. Av. General Gustavo Cordeiro de Farias, S/N, CEP: 59012-570 - Petrópolis, Natal, Rio Grande do Norte, Brasil. Tel: +55 84 3342-9807. Fax: +55 84 3342-9833. E-mail: adrirezende@yahoo.com
}

to healthy age-matched subjects (Muñoz-Torres et al., 1996; Kemink et al., 2000) markers of bone formation plasma insulin-like growth factor I (IGF-I), and a variety of bone-related changes are known to be influenced by hyperglycemia such as femoral neck geometry, microarchitecture and biomechanical markers of bone turnover (Starup-Linde, 2013; Bortolin et al., 2015; 2016). However, the association between T1DM and bone mineral density (BMD) is controversial. Some studies have demonstrated a reduced BMD (Pan et al., 2014; Kujath et al., 2015), while others have shown normal or even increased BMD (Gallacher et al., 1993; Maggio et al., 2010) in patients with T1DM compared to control subjects. 
Despite evidence that T1DM is associated with bone fragility, the mechanisms are not completely understood (Hamann et al., 2012). The discovery of nuclear factor- $\kappa \mathrm{B}$ (RANK)/RANK ligand (RANKL)/osteoprotegerin (OPG), factors involved in the control of osteoclast differentiation and osteoporosis, has advanced bone research into a new era (Boyce, Xing 2008). The RANK/RANKL/OPG system is an important signal transduction pathway that regulates bone resorption, modeling, and remodeling. The binding of OPG to RANKL inhibits binding between RANKL and RANK, thereby preventing osteoclast precursor differentiation and fusion to form mature osteoclasts (Boyce, Xing 2008).

Data from the literature indicates that $O P G$ is considered to be one of the most important candidate genes for influencing the pathogenesis of osteopathy (Song et al., 2013; Wang et al., 2013; Guo et al., 2014) particularly in postmenopausal women. It is characterized by a reduction in BMD. As an active component of this system, therefore, polymorphisms in the $O P G$ gene might influence bone metabolism and BMD (Wang et al., 2013; Guo et al., 2014) neck hip and total hip was determined by dual-energy X-ray absorptiometry (DEXA). Although several studies have investigated the association of $O P G$ single nucleotide polymorphisms (SNPs) such as $163 \mathrm{~A}>\mathrm{G}, 1181 \mathrm{G}>\mathrm{C}$, $245 \mathrm{~T}>\mathrm{G}$, and 950T $>\mathrm{C}$ with $\mathrm{BMD}$ and bone disorders (Feng et al., 2012; Liu et al., 2013; Wang et al., 2013; Yu et al., 2013; Guo et al., 2014) which is characterized by a decrease in BMD, the relationship between the $1181 \mathrm{G}>\mathrm{C}$ and $163 \mathrm{~A}>\mathrm{G}$ SNPs of the $O P G$ gene and T1DM and BMD has not yet been evaluated.

Thus, the aim of the present study was to investigate the relationship between hyperglycemia and alterations in BMD and serum bone biomarkers in individuals with $\mathrm{T} 1 \mathrm{DM}$, as well as possible associations with the $1181 \mathrm{G}>\mathrm{C}$ and $163 \mathrm{~A}>\mathrm{G} O P G$ polymorphisms.

\section{MATERIAL AND METHODS}

\section{Material}

\section{Study subjects}

This cross-sectional study included 119 individuals diagnosed with T1DM according to American Diabetes Association criteria (American Diabetes Association, 2016), aged 6 to 20 years old and receiving insulin therapy. Patients were recruited at the Endocrinology Pediatrics Unit, Pediatrics Hospital of the Federal University of Rio Grande do Norte (UFRN), in Natal, RN, Brazil. All individuals with T1DM who attended the Endocrinology Pediatrics Unit were invited to participate in the study.
A group of normoglycemic (NG) and non-diabetic individuals $(\mathrm{n}=161)$ were recruited from local public schools. Exclusion criteria for both groups included other inflammatory diseases, evidence of systemic illnesses that could affect BMD, infections, and pregnancy. The University Hospital Onofre Lopes (UFRN) Human Research Ethics Committee approved the study (protocol number 328/09). All study participants or their parents provided written informed consent prior to enrollment. After assessment of medical history, fasting blood samples were obtained from all subjects for biochemical analyses and genotyping.

\section{Biochemical measurements}

Glycemic control was assessed by measuring glycated hemoglobin in total blood and fasting serum glucose. Biomarkers of bone metabolism analyzed include alkaline phosphatase (ALP) and bone alkaline phosphatase (b-ALP) activities; in addition, total and ionized calcium and phosphorus were measured. Glucose, ALP activity, and total calcium and phosphorous tests were performed using LABTEST kits (Lagoa Santa, Brazil) and LABMAX PLENNO equipment (LABTEST). Glycated hemoglobin was measured using an RA 50 spectrophotometer (Bayer Diagnostics, Dublin, Ireland). b-ALP activity was determined by a chemiluminescent method using Liaison equipment (DiaSorin-Diagnostics, EUA); and serum ionized calcium was measured using an AVL electrolyte analyzer (Roche Diagnostics, Roswell, GA, USA).

\section{$B M D$ measurements}

The BMD of the lumbar spine (L1-L4) of each participant was determined by DEXA using a LUNARGE DPX-NT bone densitometer (Lunar Corporation, Madison, WI, USA). The assessed parameters included bone area $\left(\mathrm{BA}, \mathrm{cm}^{2}\right)$, bone mineral content $(\mathrm{BMC}, \mathrm{g})$ and BMD $\left(\mathrm{g} / \mathrm{cm}^{2}\right.$, or $\mathrm{Z}$-score $)$. In order to minimize the influence of already established height, weight, and pubertal development, a predicted mathematical model for BMD correction was applied, from which an adjusted BMD expressed in SD (Z-score) was obtained. Lumbar spine DEXA was chosen as the preferred method for BMD assessment because of the relatively low radiation doses required, as well as an overall lower cost owing to the speed of the procedure.

According to the criteria set by the Brazilian Society of Bone Densitometry for the definition of decreased BMD, the term "osteoporosis" should not be used in children and adolescents, considering only densitometric criteria. Thus, the terminology "low bone mass for chronological age" was suggested to be more 
appropriately used to characterize those individuals with Z-scores lower than -2.0 (Zerbini et al., 2007).

\section{Genotyping}

Peripheral blood mononuclear cells (PBMCs) were isolated from blood samples by discontinuous FicollHipaque (Sigma-Aldrich, St. Louis, MO, USA) gradients (specific density $1.070 \mathrm{~g} / \mathrm{mL}$ ) at room temperature. Subsequently, genomic DNA was recovered using the commercial Illustra Triple Prep kit (GE Healthcare, Little Chalfont, UK) according to the manufacturer's instructions. DNA was stored at $-20^{\circ} \mathrm{C}$ until subsequent analysis.

TaqMan allelic discrimination was performed in a 7500 Fast Real-Time PCR System (Applied Biosystems, Foster City, CA, USA) for genotyping $O P G 1181 \mathrm{G}>\mathrm{C}$ (rs2073618) and 163A>G (rs3102735) polymorphisms. These polymorphisms were detected using Applied Biosystems TaqMan pre-designed assays C_1971047_1_ and C_1971046_10, respectively. To validate the genotyping, $10 \%$ of the samples, chosen randomly, were re-genotyped.

\section{Data analysis}

The Kolmogorov-Smirnov test was performed to determine whether quantitative variables could be considered normally distributed. Differences between groups of variables with distributions considered normal were calculated with $t$ tests and ANOVA followed by Tukey's multiple comparison testing. For group comparisons of skew-distributed variables, Mann Whitney and Kruskall-Wallis followed by Dunn's tests were used. Correlation was assessed by Spearman's or Pearson's rank tests. The Chi-square test was used to test for associations between polymorphisms and study groups. These analyses were performed using Sigma Stat software version 3.5 (Systat software, Erkrath, Germany). Logistic regression analysis was implemented to evaluate the effect of genetic and non-genetic variables associated with T1DM and BMD. This part of the statistical analyses was performed by the SNPassoc package from the statistical software R version 2.15.2 ( $\mathrm{R}$ foundation for Statistical Computing, Vienna, Austria) (http://cran.r-project.org/web/packages/ SNPassoc/index.html). $p$-values $<0.05$ were considered significant.

\section{RESULTS}

\section{Clinical and biochemical data}

Table I shows biochemical and clinical data for the NG and T1DM groups. No significant difference in chronological age or sex was found between groups. As expected, serum glucose and glycated hemoglobin values were significantly higher $(p<0.001)$ in the group composed of subjects with diabetes compared to NG individuals. No difference was found in ionized calcium, phosphorus, or

TABLE I - Biochemical and clinical data for NG and T1DM groups

\begin{tabular}{lccc}
\hline Variables & $\begin{array}{c}\text { NG } \\
\boldsymbol{n}=\mathbf{1 6 1}\end{array}$ & $\begin{array}{c}\text { T1DM } \\
\boldsymbol{n}=\mathbf{1 1 9}\end{array}$ & $\boldsymbol{p}$-value \\
\hline Sex, female \% & 61.5 & 73.1 & 0.967 \\
Age, years & $11(9-15)$ & $13(9-15)$ & 0.379 \\
Time of diagnosis, years & - & $5.0 \pm 3.7$ & - \\
Age at diagnosis, years & - & $6.9 \pm 3.5$ & - \\
Glucose, mg/dL & $79(73.5-85.5)$ & $210(131-316)$ & $<\mathbf{0 . 0 0 1}$ \\
Glycated hemoglobin, \% & $5.8(5.1-6.7)$ & $9.5(7.8-12.3)$ & $<\mathbf{0 . 0 0 1}$ \\
Ionized Ca, mmol/L & $1.2(0.8-1.2)$ & $1.1(0.9-1.2)$ & 0.808 \\
Ca, mg/dL & $10(9.3-10.8)$ & $9.6(8.8-10.3)$ & $\mathbf{0 . 0 0 2}$ \\
Phosphorus, mg/dL & $4.6 \pm 1.1$ & $4.4 \pm 1.3$ & 0.191 \\
ALP, U/L & $234.9 \pm 133.7$ & $253.9 \pm 122.2$ & 0.215 \\
b-ALP, $\mu$ g/L & $68.4 \pm 39.5$ & $75.7 \pm 39.2$ & 0.390 \\
BMD, Z-score & $0.2 \pm 0.9$ & $-0.8 \pm 1.2$ & $<\mathbf{0 . 0 0 1}$ \\
\hline
\end{tabular}

Results are shown as mean \pm standard deviation or median (interquartile range), unless otherwise indicated. Significant $p$-values are shown in bold. NG, normoglycemic; T1DM, type 1 Diabetes mellitus; ALP, alkaline phosphatase; b-ALP, bone alkaline phosphatase; BMD, bone mineral density. 
ALP or b-ALP activity between groups. Total calcium was significantly lower in patients with T1DM when compared to NG individuals $(p=0.002)$. ALP activity showed a negative correlation with time of diagnosis $(\mathrm{r}=-0.35$, $p=0.01)$ and glycated hemoglobin $(\mathrm{r}=-0.30, p=0.026)$.

\section{BMD data}

BMD, expressed as a Z-score, was lower in the T1DM compared to the NG group $(p<0.001)$ as shown in Table I. In an effort to understand the relationship between poor glycemic control and bone density in T1DM, a correlation analysis was performed. A significant negative correlation was observed between BMD and glucose $(\mathrm{r}=$ $-0.28, p=0.029)$; ionized calcium was significantly and negatively correlated with BMD $(\mathrm{r}=-0.29, p=0.04)$.

Of the 119 patients with T1DM studied, 13 (11\%) showed "low bone density for chronological age" (BMD: $-2.0 \pm 1.8$ ) and had poor glycemic control at the time of sample collection (glucose: $205.5 \pm 126.7 \mathrm{mg} / \mathrm{dL}$; glycated hemoglobin: $10.6 \pm 3.1 \%$ ). The average age and age at diagnosis of these patients was $13.0 \pm 4.5$ and $7.9 \pm 2.9$ years, respectively, and the average time of diagnosis was following $3.5(1.1-5.3)$ years of diabetes.

\section{OPG polymorphisms in the T1DM and NG groups}

Hardy-Weinberg equilibrium was verified for the two polymorphisms examined in the NG and T1DM groups. Randomly re-genotyped samples confirmed previously established genotypes with no discrepancies. Table II shows genotypic and allelic distributions for $O P G$ $1181 \mathrm{G}>\mathrm{C}$ and $163 \mathrm{~A}>\mathrm{G}$ polymorphisms.
For the allelic distributions of $O P G 1181 \mathrm{G}>\mathrm{C}$, we found that the $\mathrm{C}$ allele was less frequent in the T1DM group, although this finding was not statistically significant $(p=0.054)$. No association was found following analyses of the polymorphisms according to different genetic models. Table III presents the genetic models with the lowest $p$-values for each polymorphism examined.

As the number of patients with altered BMD was not adequate to establish a separate group with sufficient power for analysis, in order to investigate the relationship of each polymorphism with bone alterations, we evaluated markers of glycemic control and bone biomarkers in the subjects with T1DM according to their genotype (Table IV). For the $O P G 1181 \mathrm{G}>$ C polymorphism, the level of ionized calcium was significantly increased $(p=0.036)$ in $\mathrm{CC}$ compared to $\mathrm{GG}+\mathrm{GC}$ carriers.

\section{DISCUSSION}

In this study, patients with T1DM displayed poor glycemic control, and were therefore subjected to a higher risk of developing diabetic complications such as osteopathy. This is consistent with previous studies which demonstrated that prolonged exposure to hyperglycemia can promote changes in bone turnover, primarily in bone formation, leading to a decrease in bone mass, which can in turn result in short-term bone fragility and osteopenia/ osteoporosis (Gunczler et al., 1998; Gogas Yavuz et al., 2011; Loureiro et al., 2014).

The pathogenesis of diabetic osteopathy is not completely understood. However, it seems reasonable to suppose that a combination of factors including genetic, nutritional, hormonal, environmental, physiological

TABLE II - Frequencies of genetic polymorphisms in T1DM and NG groups

\begin{tabular}{|c|c|c|c|c|}
\hline Polymorphism & Genotype/Allele & $\begin{array}{c}\text { NG } \\
\text { n (\%) }\end{array}$ & $\begin{array}{l}\text { T1DM } \\
\text { n (\%) }\end{array}$ & $p$-value \\
\hline \multirow{5}{*}{$\begin{array}{l}O P G 1181 G>C \\
(\mathrm{rs} 2073618)\end{array}$} & GG & $59(36.6)$ & $47(39.5)$ & 0.888 \\
\hline & GC & $75(46.6)$ & $53(44.5)$ & \\
\hline & $\mathrm{CC}$ & $27(16.8)$ & $19(16.0)$ & \\
\hline & $\mathrm{G}$ & $145(52,9)$ & $147(85)$ & 0.054 \\
\hline & $\mathrm{C}$ & $129(47,1)$ & $91(15)$ & \\
\hline \multirow{5}{*}{$\begin{array}{l}O P G 163 A>G \\
(\mathrm{rs} 3102735)\end{array}$} & AA & $112(72.3)$ & $84(71.8)$ & 0.960 \\
\hline & AG & $41(26.5)$ & $31(26.5)$ & \\
\hline & GG & $2(1.3)$ & $2(1.7)$ & \\
\hline & A & 265 & 199 & 0.983 \\
\hline & $\mathrm{G}$ & 45 & 35 & \\
\hline
\end{tabular}

NG, normoglycemic; T1DM, type 1 Diabetes mellitus. 
Relationship between glycemic control and OPG gene polymorphisms

TABLE III - Genotype distribution of polymorphisms in the studied groups according to genetic models

\begin{tabular}{|c|c|c|c|c|c|}
\hline Polymorphism & Genetic model & $\begin{array}{c}\text { NG } \\
\text { n (\%) }\end{array}$ & $\begin{array}{l}\text { T1DM } \\
\text { n (\%) }\end{array}$ & OR (95\% CI) & $p$-value \\
\hline \multirow{3}{*}{$\begin{array}{l}O P G 1181 G>C \\
(\mathrm{rs} 2073618)\end{array}$} & Recessive & & & & \\
\hline & $\mathrm{GG}+\mathrm{GC}$ & $134(83.2)$ & $100(84.0)$ & 1 & 0.857 \\
\hline & $\mathrm{CC}$ & $27(16.8)$ & $19(16.0)$ & $0.94(0.5-1.79)$ & \\
\hline \multirow{3}{*}{$\begin{array}{l}O P G 163 A>G \\
(\mathrm{rs} 3102735)\end{array}$} & Recessive & & & & \\
\hline & $\mathrm{AA}+\mathrm{AG}$ & $153(98.7)$ & 115 (98.3) & 1 & 0.777 \\
\hline & GG & $2(1.3)$ & $2(1.7)$ & $1.33(0.18-9.59)$ & \\
\hline
\end{tabular}

Genetic models with the lowest $p$-values for each studied polymorphism are presented. NG, normoglycemic; T1DM, type 1 Diabetes mellitus; OR, odds ratio; $\mathrm{CI}$, confidence interval.

TABLE IV - Biochemical parameters according to studied polymorphism genotypes in patients with T1DM

\begin{tabular}{|c|c|c|c|c|c|c|c|c|}
\hline Polymorphism & $\begin{array}{l}\text { Glucose } \\
\text { mg/dl }\end{array}$ & $\begin{array}{c}\text { Glycated } \\
\text { hemoglobin } \\
\% \\
\end{array}$ & $\begin{array}{l}\text { Ionized } \\
\text { calcium } \\
\mathrm{mmol} / \mathrm{L} \\
\end{array}$ & $\begin{array}{l}\text { Calcium } \\
\text { mg/dL }\end{array}$ & $\begin{array}{c}\text { Phosphorus } \\
\text { mg/dL }\end{array}$ & $\begin{array}{l}\text { ALP } \\
\mathbf{U} / \mathbf{L}\end{array}$ & $\begin{array}{l}\text { b-ALP } \\
\mu \mathrm{g} / \mathrm{L}\end{array}$ & $\begin{array}{c}\text { BMD } \\
Z \text {-score }\end{array}$ \\
\hline \multicolumn{9}{|l|}{$\begin{array}{l}O P G 1181 G>C \\
(\mathrm{rs} 2073618)\end{array}$} \\
\hline \multicolumn{9}{|l|}{ Recessive } \\
\hline $\mathrm{GG}+\mathrm{GC}$ & $227.8 \pm 111.6$ & $\begin{array}{c}9.5 \\
(7.9-11.6)\end{array}$ & $\begin{array}{c}1.0 \\
(0.8-1.2)\end{array}$ & $\begin{array}{c}9.7 \\
(8.8-10.6)\end{array}$ & $\begin{array}{c}4.3 \\
(3.7-4.9)\end{array}$ & $\begin{array}{c}229.6 \\
(154.0-350.0)\end{array}$ & $\begin{array}{c}69.0 \\
(25.2-106.9)\end{array}$ & $-0.7 \pm 1.2$ \\
\hline $\mathrm{CC}$ & $228 \pm 118.8$ & $\begin{array}{c}10.3 \\
(7.6-13.5)\end{array}$ & $\begin{array}{c}1.2 \\
(1.0-1.2)\end{array}$ & $\begin{array}{c}9.4 \\
(8.8-10.1)\end{array}$ & $\begin{array}{c}4.0 \\
(3.6-4.9)\end{array}$ & $\begin{array}{c}203 \\
(150.0-228.2)\end{array}$ & $\begin{array}{c}82.1 \\
(33.7-105.8)\end{array}$ & $-1.4 \pm 1.3$ \\
\hline$p$-value & 0.995 & 0.673 & 0.036 & 0.414 & 0.218 & 0.130 & 0.821 & 0.125 \\
\hline \multicolumn{9}{|l|}{$\begin{array}{l}O P G 163 A>G \\
(\mathrm{rs} 3102735)\end{array}$} \\
\hline \multicolumn{9}{|l|}{ Dominant } \\
\hline $\mathrm{AA}$ & $226.7 \pm 111.3$ & $\begin{array}{c}9.7 \\
(7.8-12)\end{array}$ & $1.0 \pm 0.2$ & $\begin{array}{c}9.6 \\
(8.7-10.6)\end{array}$ & $\begin{array}{c}4.3 \\
(3.6-4.9)\end{array}$ & $\begin{array}{c}211 \\
(159.4-322.4)\end{array}$ & $\begin{array}{c}69 \\
(22.9-88.7)\end{array}$ & $-0.9 \pm 1.0$ \\
\hline $\mathrm{AG}+\mathrm{GG}$ & $221.7 \pm 114.3$ & $\begin{array}{c}9.4 \\
(8.3-11.9)\end{array}$ & $1.0 \pm 0.2$ & $\begin{array}{c}9.9 \\
(9.3-10.3)\end{array}$ & $\begin{array}{c}4.1 \\
(3.8-4.8)\end{array}$ & $\begin{array}{c}207.8 \\
(145.2-336)\end{array}$ & $\begin{array}{c}113.2 \\
(40.3-120.0)\end{array}$ & $-0.5 \pm 1.5$ \\
\hline$p$-value & 0.834 & 0.958 & 0.344 & 0.274 & 0.879 & 0.586 & 0.051 & 0.291 \\
\hline
\end{tabular}

Results are shown as mean \pm standard error or median (interquartile range). Significant $p$-values are shown in bold. ALP, alkaline phosphatase; b-ALP, bone alkaline phosphatase; BMD, bone mineral density.

and acquired diseases influence bone development and maintenance, and each has a different impact on bone quantity as well as metabolic mechanism (Paula, Horowitz, Rosen, 2010; Gogas Yavuz et al., 2011). Several hypotheses have been be considered for the mechanism of diabetic osteopathy, including accelerated aging in the bone marrow compartment due to enhanced reactive oxygen species, direct glucose toxicity to osteoblasts and changes in circulating calciotropic hormones or growth factors (Paula, Horowitz, Rosen, 2010). With respect to the latter, we recently showed that $I G F 1, I G F 1$ receptor (IGF1R) and transforming growth factor beta 1 (TGFB1)
mRNA expression associated with poor glycemic control lead to a decreased anabolic effect of these genes in the bone tissue; this may negatively affect bone mass peak acquisition and result in a low BMD (Souza et al., 2016).

In our study, BMD was decreased in the T1DM group, a result suggestive that bone development occurs in parallel with the presence of diabetes and might induce fragility and a reduced peak bone mass in patients with T1DM, resulting in a deficit in bone mass which may manifest as osteopenia in the growing bone. This hypothesis is supported by the inverse correlation we observed between BMD and serum glucose, as well as 
by the negative correlation between ionized calcium and BMD seen in patients with T1DM. Is important to note that among the 119 subjects with diabetes studied, approximately $11 \%$ had already lost bone mass. Therefore, the individuals who presented with low bone density for their chronological age might also be supposed to exhibit bone microarchitecture fragility with a concomitant higher risk of fractures and lower peak bone mass. Additionally, ALP activity showed a negative correlation with time of diagnosis and glycated hemoglobin in the T1DM group supports the idea that chronic hyperglycemia might lead to suppressed bone turnover and thus potentially fragile bones.

Data on bone density in T1DM are controversial. Although the present findings are in agreement with a few previous studies (Gunczler et al., 1998; Gogas Yavuz et al., 2011; Loureiro et al., 2014; Souza et al., 2016), others found no significant decrease in BMD in individuals with T1DM when compared to controls (Bechtold et al., 2006; Brandao et al., 2007; Amorim et al., 2008; Maggio et al., 2010; Simmons et al., 2011). Some of these studies had limitations, such as sample sizes not sufficient to draw definitive conclusions regarding BMD. In study performed by Brandão et al. (2007), children and adolescents with T1DM have normal bone mass in their lumbar spines; however, these researchers demonstrated that longer diabetes duration and poor metabolic control might have a negative impact on bone mass, requiring further investigation through longitudinal studies (Brandao et al., 2007). In agreement with our results, Gunczler et al., (1998) suggested that T1DM in children was associated with low bone turnover resulting in a decline in bone mass, which might manifest as osteopenia in the growing bone (Gunczler et al., 1998). Pan et al. (2014), in a metaanalysis of cross-sectional studies, reports that T1DM is associated with a significantly lower BMD overall, and BMD (including total body, spine and femur) differences were also observed in patients $<20$ years old. However, bone loss among patients with T1DM $<20$ years old suggested that BMD may decrease relatively early in the course of the disease (Pan et al., 2014). Notably, osteopenia has been reported at the onset of T1DM, suggesting the existence of pathogenic mechanisms that operate before the overt manifestation of T1DM. It is established that islet cell destruction and insulinopenia begin several years before the onset and clinical recognition of disease. Therefore, it is possible that some of the autoimmune and auto-inflammatory responses, occurring before and after the onset of diabetes, may play a role in bone loss (Pan et al., 2014).

Many previous studies have reported that genetic factors play key roles in the pathogenesis of osteopathy and low BMD. The $O P G$ gene has been verified as being involved in bone remodeling, bone mineral homeostasis, and bone matrix composition (Liu et al., 2013) neck, and total hip by DEXA. However, to date, no studies have been published that evaluate the relationship of the $1181 \mathrm{G}>\mathrm{C}$ and $163 \mathrm{~A}>\mathrm{G}$ SNPs of the $O P G$ gene with BMD in patients with T1DM, despite evidence that these polymorphisms are associated with a loss of bone mass (Shang et al., 2013; Song et al., 2013). Our results, following an examination of the $O P G$ polymorphisms in the T1DM group, demonstrate no association with alterations in BMD and bone biomarkers, but revealed that the levels of ionized calcium were increased in carriers of the $O P G$ $1181 G>C$ polymorphism CC genotype, when compared to carriers of the $\mathrm{GG}+\mathrm{GC}$ genotypes, suggesting that this polymorphism might favor osteoclastogenesis.

In order to elucidate the true contribution of $O P G$ polymorphisms to the development of bone alterations in T1DM, further studies with larger samples of patients are needed. These will improve our understanding of the contribution of this and other genes to bone mass status and allow the development of preventive and/or therapeutic interventions in T1DM.

\section{CONCLUSION}

In summary, we demonstrated that prolonged hyperglycemia resulting from T1DM is a negative factor in bone metabolism, which leads to an imbalance in bone homeostasis. In addition, children and adolescents presenting with an early onset of T1DM may possess a bone mass peak lower than that of healthy subjects and consequently impaired growth, factors that make these individuals more prone to fractures, increasing the risk of osteoporosis in adult age. Despite the lack of a detected association between $O P G 1181 \mathrm{G}>\mathrm{C}$ and $163 \mathrm{~A}>\mathrm{G}$ polymorphisms and BMD in patients with T1DM, increased ionized calcium in those carrying $\mathrm{CC}$ genotypes for the $O P G 1181 \mathrm{G}>\mathrm{C}$ polymorphism suggests a possible increase in osteoclastogenesis, which may be caused by the lower BMD observed in these subjects. Thus, our results contribute to the efforts to address the research gap in the elucidation of factors associated to the bone fragility of patients with T1DM and to improve their bone health.

\section{ACKNOWLEDGEMENTS}

This study was supported by grants from $\mathrm{CNPq}$ (620099/2008-9). M.H.H. and R.D.C.H. are recipients of fellowships from CNPq, Brazil. M.B.L, M.A.G.U., 
K.S.C.S. and R.H.B are recipients of fellowships from CAPES, Brazil. We are thankful for the technical support provided by students from the LABMULT/UFRN/RN. We thank all the physicians, nurses, and hospital staff at HOSPED/UFRN who were involved in the study. The authors also thank all children, adolescents, and young adults with type- 1 diabetes and their parents who gave their consent and participated in the study.

\section{CONFLICT OF INTEREST} interest.

The authors declare that they have no conflict of

\section{REFERENCES}

American Diabetes Association. Standards of Medical Care in Diabetes - 2016. Diabetes Care. 2016;39(Supp 1):S1-112.

Amorim FPLG, Ornelas SS, Diniz SF, Batista AC, Silva TA. Imbalance of RANK, RANKL and OPG expression during tibial fracture repair in diabetic rats. J Mol Histol. 2008;39(4):401-8.

Bechtold S, Dirlenbach I, Raile K, Noelle V, Bonfig W, Schwarz HP. Early manifestation of type 1 diabetes in children is a risk factor for changed bone geometry: data using peripheral quantitative computed tomography. Pediatrics. 2006;118(3):e627-34.

Bortolin RH, Freire Neto FP, Arcaro Filho CA, Bezerra JF, da Silva FS, Ururahy MAG, et al. Anabolic effect of insulin therapy on the bone: osteoprotegerin and osteocalcin up-regulation in streptozotocin-induced diabetic rats. Basic Clin Pharmacol Toxicol. 2016;120(3):227-234.

Bortolin RH, da Graça Azevedo Abreu BJ, Abbott Galvão Ururahy M, Costa de Souza KS, Bezerra JF, Loureiro MB, et al. Protection against T1DM-Induced bone loss by zinc supplementation: biomechanical, histomorphometric, and molecular analyses in STZ-induced Diabetic rats. PLoS One. 2015;10(5):e0125349.

Boyce BF, Xing L. Functions of RANKL/RANK/OPG in bone modeling and remodeling. Arch Biochem Biophys. 2008;473(2):139-46.

Brandao FR, Vicente EJ, Daltro CH, Sacramento M, Moreira A, Adan L. Bone metabolism is linked to disease duration and metabolic control in type 1 diabetes mellitus. Diabetes Res Clin Pract. 2007;78(3):334-9.
Feng G, Meng L, Wang H, Lu Y, Jia J, Zhang Y, et al. Singlenucleotide polymorphism of the osteoprotegerin gene and its association with bone mineral density in Chinese postmenopausal women. J Pediatr Endocrinol Metab. 2012;25(11-12):1141-4.

Gallacher SJ, Fenner JA, Fisher BM, Quin JD, Fraser WD, Logue FC, et al. An evaluation of bone density and turnover in premenopausal women with type 1 diabetes mellitus. Diabet Med. 1993;10(2):129-33.

Gogas Yavuz D, Keskin L, Kıyıcı S, Sert M, Yazıcı D, Sahin I, et al. Vitamin D receptor gene BsmI, FokI, ApaI, TaqI polymorphisms and bone mineral density in a group of Turkish type 1 diabetic patients. Acta Diabetol. 2011;48(4):329-36.

Gunczler P, Lanes R, Paz-Martinez V, Martinis R, Esaa S, Colmenares V, et al. Decreased lumbar spine bone mass and low bone turnover in children and adolescents with insulin dependent Diabetes Mellitus followed longitudinally. J Pediatr Endocrinol Metab. 1998;11(3):413-9.

Guo L, Tang K, Quan Z, Zhao Z, Jiang D, Library C. Association between seven common OPG genetic polymorphisms and osteoporosis risk: ameta-analysis. DNACeel Biol.2014;33(1):29-39.

Hamann C, Kirschner S, Günther K, Hofbauer LC. Bone, sweet bone-osteoporotic fractures in diabetes mellitus. Nat Rev Endocrinol. 2012;8(5):297-305.

Kemink SA, Hermus AR, Swinkels LM, Lutterman JA, Smals AG. Osteopenia in insulin-dependent diabetes mellitus; prevalence and aspects of pathophysiology. J Endocrinol Invest. 2000;23(5):295-303.

Kujath AS, Quinn L, Elliott ME, LeCaire TJ, Binkley N, Molino AR, et al., Different health behaviours and clinical factors associated with bone mineral density and bone turnover in premenopausal women with and without type 1 diabetes. Diabetes Metab Res Rev. 2015;31(4):421-32.

Liu S, Yi Z, Ling M, Shi J. Association between g.19163A>G and g.23298T $>C$ genetic variants of the osteoprotegerin gene and bone mineral density in Chinese women. Hormones (Athens). 2013;12(4):578-83.

Loureiro MB, Ururahy MAG, Freire-Neto FP, Oliveira GHM, Duarte VMG, Luchessi AD, et al. Low bone mineral density is associated to poor glycemic control and increased OPG expression in children and adolescents with type 1 diabetes. Diabetes Res Clin Pract. 2014;103(3):452-7. 
Maggio AB, Ferrari S, Kraenzlin M, Marchand LM, Schwitzgebel V, Beghetti M, et al. Decreased bone turnover in children and adolescents with well controlled type 1 diabetes. $\mathrm{J}$ Pediatr Endocrinol Metab. 2010;23(7):697-707.

Muñoz-Torres M, Jódar E, Escobar-Jiménez F, López-Ibarra PJ, Luna JD. Bone mineral density measured by dual X-ray absorptiometry in Spanish patients with insulin-dependent diabetes mellitus. Calcif Tissue Int. 1996;58(5):316-9.

Pan H, Wu N, Yang T, He W. Association between bone mineral density and type 1 diabetes mellitus: a meta-analysis of crosssectional studies. Diabetes Metab Res Rev. 2014;30(7):531-42.

Paula FJA, Horowitz MC, Rosen CJ. Novel insights into the relationship between diabetes and osteoporosis. Diabetes Metab Res Rev. 2010;26(8):622-30.

Shang M, Lin L, Cui H. Association of genetic polymorphisms of RANK, RANKL and OPG with bone mineral density in Chinese peri- and postmenopausal women. Clin Biochem. 2013;46(15):1493-501.

Simmons JH, Raines M, Ness KD, Hall R, Gebretsadik T, Mohan S, et al. Metabolic control and bone health in adolescents with type 1 diabetes. Int J Pediatr Endocrinol. 2011;2011(1):13.

Song JF, Jing ZZ, Hu W, Su YX. Association between single nucleotide polymorphisms of the osteoprotegerin gene and postmenopausal osteoporosis in Chinese women. Genet Mol Res. 2013;12(3):3279-85.
Souza KSC, Ururahy MAG, da Costa Oliveira YM, Loureiro MB, da Silva HPV, Bortolin RH, et al. Low bone mineral density in patients with type 1 diabetes: association with reduced expression of IGF1, IGF1R and TGF B 1 in peripheral blood mononuclear cells. Diabetes Metab Res Rev. 2016;32(6):58995.

Starup-Linde J. Diabetes, biochemical markers of bone turnover, diabetes control, and bone. Front Endocrinol (Lausanne). 2013;4:21.

Wang Q, Chen Z, Huang Y, Li Q, Zhu L, Cai X, et al. The relationship between osteoprotegerin gene polymorphisms and bone mineral density in Chinese postmenopausal women. Int Immunopharmacol. 2013;17(2):404-7.

Yu F, Huang X, Miao J, Guo L, Tao D. Association between osteoprotegerin genetic variants and osteoporosis in Chinese postmenopausal women. Endocr J. 2013;60(12):1303-7.

Zerbini CAF, Pippa MGB, Eis SR, Lazaretti-Castro M. Densitometria clínica: Posições oficiais 2006. Rev Bras Reum. 2007;47(1):25-33.

Received for publication on $28^{\text {th }}$ November 2016 Accepted for publication on $02^{\text {nd }}$ June 2017 